\title{
A CONSTRUÇÃO DE UM MODELO PARA O ENSINO DE ECOLOGIA EM UNIDADES DE CONSERVAÇÃO: O CASO DO PARQUE ECOLÓGICO DIVA PAIM BARTH, MUNICIPIO DE TOLEDO, PARANÁ
}

\author{
Antônio Fernandes Nascimento Junior ${ }^{1}$ \\ André Maciel da Silva ${ }^{2}$
}

\begin{abstract}
RESUMO O objetivo deste trabalho consiste em analisar e avaliar o potencial do Parque Ecológico Diva Paim Barth do município de Toledo, PR, como instrumento pedagógico para a educação ambiental e o ensino da ecologia. A partir desta preocupação foi feito um estudo documental e, posteriormente, a identificação da megafauna e da flora do parque. Em seguida, foram identificados alguns aspectos da ecologia comportamental possíveis de serem observados por alunos do ensino fundamental e médio. Estes dados forneceram subsídios para a produção de alguns recursos pedagógicos. Diante de tais resultados, o parque revelou-se capaz de ser utilizado como um laboratório natural fornecedor de um modelo pedagógico para a ecologia e educação ambiental possível de ser utilizado por professores, pesquisadores e alunos.
\end{abstract}

PALAVRAS-CHAVE: Horto Florestal. Laboratório Natural. Educação Ambiental.

\section{THE CONSTRUCTION OF A MODEL FOR THE TEACHING OF ECOLOGY ON CONSERVATION UNITIES: THE CASE OF THE ECOLOGICAL PARK DIVA PAIM BARTH, OF THE CITY OF TOLEDO, PARANÁ}

\begin{abstract}
The objective of this paper consists on the analysis and evaluation of the potential of the ecological park Diva Paimbarth of the city of Toledo, PR, as an pedagogical instrument for environmental education and ecology teaching. From this concern, a documental study was done and, after that, the identification of the megafauna and flora of the park. Then, some of the aspects of the comportamental ecology, possible of being observed by students of middle and high schools, were identified. These data provided support for the production of some pedagogical resources. With such results, the park revealed itself capable of being used as a natural laboratory, providing a
\end{abstract}

\footnotetext{
${ }^{1}$ Professor Adjunto do Departamento de Biologia da Universidade Federal de Lavras. toni_nascimento@hotmail.com

${ }^{2}$ Graduando em Ciências Biológicas (Licenciatura), Universidade Federal de Lavras, MG. andremaciel_29@hotmail.com
} 
pedagogical model for the ecology and environmental education, possible of being used by teachers, researchers and students.

KEY-WORDS: Garden forest. Natural laboratory. Environmental Education.

\section{LA CONSTRUCCIÓN DE UN MODELO PARA LA ENSEÑANZA DE ECOLOGÍA EN ÁREAS PROTEGIDAS: CASO DEL PARQUE ECOLÓGICO DIVA PAIMBARTH, CIUDAD DE TOLEDO, PARANÁ}

\section{RESUMEN}

El objetivo de este estudio es analizar y evaluar el potencial del Parque Ecológico Diva Paim Barth de la ciudad de Toledo, PR, como una herramienta educativa para la educación ambiental y la educación ecológica. De esta preocupación se hizo un estudio documental y posteriormente la identificación de la megafauna y flora del parque. A continuación, hemos identificado algunos aspectos de la ecología del comportamiento posibles para ser observado por los estudiantes de las escuelas primarias y secundarias. Estos datos proporcionan subsidios para la producción de algunos recursos pedagógicos. Ante estos resultados, el parque ha demostrado ser capaz de ser utilizado como un proveedor laboratorio natural de un modelo pedagógico para la ecología y la educación ambiental que puede ser utilizado por profesores, investigadores y estudiantes.

PALABRAS-CLAVE: Jardín florestal. Laboratorio natural. Educación Ambiental.

\section{INTRODUÇÃO E OBJETIVOS}

Segundo Silva (1983), numa época em que tanto se fala em preservação do meio ambiente, a sociedade brasileira começa a descobrir a importância que representa estas unidades de conservação como forma de uso e ocupação dos solos. Estas, já não são mais vistas como áreas estanques para o desenvolvimento e progresso, mas como as derradeiras alternativas de manutenção do ambiente natural, contribuindo para perpetuar espécies de animais e vegetais, melhorar o ciclo das águas, regular o regime de chuvas, evitar erosões e assoreamentos de rios, lagos, canais e mares, bem como propiciar a investigação cientifica, a educação ambiental e a recreação em ambientes silvestres.

A ecologia pode ser estudada sobre diferentes enfoques: quanto à concepção de natureza e de mundo, quanto método empregado e quanto ao interesse por um determinado objetivo de pesquisa (COLOGNESE, et al. 2001).

A falta de material e, principalmente, de um espaço adequado ao estudo de ecologia, faz com que muitas instituições de ensino encontram dificuldades quanto à formação do futuro profissional (KLEIN, et al. 2002). 
Por outro lado, Milano (1993) afirma que a evolução do tratamento das áreas protegidas, as unidades de conservação, caminha em direção ao conceito de sistema de unidades de conservação. Este conceito parte do princípio que, havendo diferentes objetivos e diferentes características de ecossistemas, somente planejando e administrando o conjunto como um todo será possível alcançar a totalidade dos objetivos conservacionistas.

Conforme Vasconcello (1997), para fazer frente aos problemas ambientais atuais e indispensáveis, precisa-se de uma educação que não só sensibilize, mas que também modifique as atitudes das pessoas e propicie novos conhecimentos, proporcionandoIhes uma nova prática a partir de reflexões de cada ser humano.

O ideal dessa nova educação seria a ênfase aos problemas atuais e urgentes, de modo a preparar a população para viver e se desenvolver em um mundo independente e em harmonia com as leis da natureza (PORTO, 1996).

As instituições de ensino fundamental, médio e superior, normalmente, pecam por não oferecer oportunidades e nem locais adequados para a realização de atividades práticas em ecologia e educação ambiental. Nesse sentido, o horto florestal vem de encontro com essa lacuna, estando de acordo com Callai, (1998) que critica as disciplinas tradicionais por não se mostrarem suficientes para tratar temas importantes e urgentes como a ecologia, presente no dia-a-dia da população, como um todo.

Por sua vez, Santiago e Saito (1995) citam que, a educação ambiental está intimamente ligada à tomada de consciência dos processos que operam na sociedade e que se manifestam através das práticas cotidianas, institucionais ou não.

Diante disso, o objetivo deste trabalho consiste em analisar e avaliar o potencial do laboratório natural do parque ecológica Diva Paim Barth como instrumento pedagógico na construção de um modelo pedagógico para o ensino da ecologia e educação ambiental.

\section{DESENVOLVIMENTO}

\subsection{A descrição da área em estudo}

O Parque Ecológico Diva Paim Barth localizada na região central do perímetro urbano. A localização geográfica do município de Toledo esta compreendida entre a

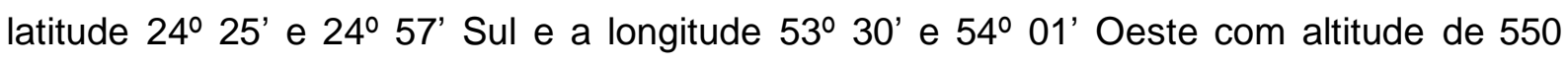
metros (COLOGNESE, 1999). Apresenta uma área de 20 ha e dispõe, em seu interior, área verde conhecida como horto florestal (local desta pesquisa), algumas espécies de animais, lago, trilhas para caminhadas e outras infraestruturas. 
Este espaço é considerado uma área de preservação ambiental (APA), sendo considerada como reserva legal, pois, é formada por várias espécies de plantas nativas da região e algumas espécies de outras regiões do País.

O Parque Ecológico possui uma cobertura arbórea característica desta região (tipologia). A vegetação apresenta características de uma floresta primária alterada, onde sobressaem árvores de grande porte, típicos do estágio clímax, que se alteram com outras espécies típicas de fases à abertura natural de clareiras. Possui, ainda, uma trilha que o circula em toda sua periferia.

\subsection{Procedimento}

Em primeiro lugar buscaram-se os documentos ligados à caracterização e construção do Parque nos arquivos da prefeitura do município de Toledo. Num segundo momento o estudo se voltou para as características ambientais do Parque.

Em seguida à esta análise foi feito um levantamento florístico determinando espécies herbáceas, arbustivas e arbóreas do Parque. As identificações foram feitas em campo com visitas semanas. Para cada espécie desconhecida foi realizada coleta e herborização para identificação posterior. O material fértil herborizado e devidamente determinado faz parte do acervo do herbário foi depositado no laboratório botânico da Universidade Paranaense, UNIPAR Campus Toledo, PR. A bibliografia utilizada foi Ellmberg, e Muller-Dombois (1965/66)

O levantamento florístico foi restrito as espécies mais características de cada estádio sucessional, as espécies ripícolas e aquelas que possuíam relevante beleza e potencial de serem exploradas.

Logo após foi realizado o levantamento e caracterização da área para identificação das espécies de animais, através de observações diretas e indiretas, com uso de material fotográfico e binóculo, onde se obteve um acervo fotográfico possibilitando mais tarde analise de conceitos tais como: 1) Ecologia Fisiológica; 2) Ecologia de Populações; 3) Comunidade ecológica; 4) Interações entre fauna e flora; 5) Ecologia comportamental.

Foi feito o levantamento bibliográfico para conhecimento das espécies de plantas tomando como critério tipo de solo, clima, ciclo anual ou perene, época de florada, tipo de flor, fruto e semente, porte arbustivo, médio ou alto, planta competitiva ou de ação alelopática.

Para determinação da maior altura dos exemplares das espécies existentes, deverá ser utilizada bibliografia específica, em que descreve metodologia para esse 
procedimento, também realizar levantamento dos maiores diâmetros encontrados nas espécies existentes na área do Parque (Blumen Leiss e Hypsometro).

\subsection{O que revelam os documentos}

Como resultado do estudo documental, foram recolhidas diversas fotografias da construção do parque, algumas históricas, tais como os primeiros passos da construção como a formação de valas. Além disso, foram coletados dados sobre as primeiras árvores plantadas e entrevistas com antigos funcionários sendo alguns de grande importância como o topógrafo Henrique Ice Heguer. Ele foi autor e mentor da obra que relatou todas as etapas da construção, que teve início em 1980, quando o então prefeito Albino Corazza Neto, em seu primeiro mandato, juntamente com seu secretariado, entrou em acordo com a Proprietária Diva Paim Barth que doou o terreno, cabendo à prefeitura a distribuição de verba para o início das atividades da obra.

Conforme os documentos, num primeiro momento o horto que era um banhado, chamado banhado-da-dona-Diva, repleto de minas, inúmeras nascentes de água, possuía uma vegetação dominante de gramíneas e pteridófitas. O solo era turfoso apresentando grande quantidade de matéria orgânica, formando assim um solo bastante ácido. O terreno sofreu um processo de drenagem, valas feitas por tratores que para se manterem sobre o solo tinham que ficar sobre fileiras de madeira, chamada estiva.

Os diversos drenos feitos possibilitaram um direcionamento, sendo toda água canalizada para a parte exterior do horto, onde mais tarde formou-se o lago municipal. Em seguida ouve a necessidade de aterrar o local, sendo este realizado em um longo período, no qual como substrato, terras vindas do interior do município e restos de construções como tijolos, solos que formaram as características atuais, que lentamente preencheram o espaço do horto.

Quando se constatou o enxugamento em partes do terreno e a correção do solo, iniciou-se o plantio das árvores, que se deu principalmente com plantas da região, valorizando as frutíferas. Outras foram introduzidas, provenientes de outras regiões do país.

Passado mais de dez anos, após uma visualização da sua fisiologia constatou-se que a flora atual sofreu várias adaptações, fornecendo uma variação no desenvolvimento da cobertura arbórea. Isto fica claro, quando se encontra plantas da mesma idade, mas em lugares diferentes dentro do parque, apresentando características totalmente diferentes, isto devido às características do solo, uma vez que seu solo é introduzido. 
Muitas espécies morreram devido a não adaptação, outras não se desenvolveram totalmente, principalmente a vegetação introduzida.

\subsection{As características atuais}

As observações diretas revelaram que a flora atual é variada, composta por uma floresta verde nativa semidecidual. Possui em seu interior nascentes e grande quantidade de plantas frutíferas nativas, com um total de aproximadamente 9,6 ha sendo a mesma protegida por uma tela percorrendo todo o perímetro do horto. Sua vegetação atual apresenta as seguintes plantas, como mostra a tabela $n^{\circ} 01$.

Tabela 01. A diversidade florística encontrada atualmente no horto.

\begin{tabular}{|l|l|}
\hline NOME POPULAR & NOME CIENTÍFICO \\
\hline Araçá & Psidium catheianum \\
\hline Aroeira do Paraná & Schinus terenbentifolius \\
\hline Aroeira periquita & Schinus molle \\
\hline Canafístula & Pelthophorum dubium \\
\hline Cássia Pirula & Cassia sp. \\
\hline Cereja & Eugenia involucrata \\
\hline Embauva & Cecropia adenocus \\
\hline Gapororoca & Rapania umbelata \\
\hline Goiaba & Psipium guaiava \\
\hline Guabiroba & Campomansia xanthocarpa \\
\hline Ingá & Ingá sessiles \\
\hline Ipê amarelo & Tabebuia crisotricha (caramba) \\
\hline Ipê roxo & Tabebuia Alba \\
\hline Ipê branco & Tabebuia avellanedea (impetiginosa) \\
\hline Leucena & Leucaena leucocephala \\
\hline Ligustro & \\
\hline
\end{tabular}


da Alta Paulista

\begin{tabular}{|l|l|}
\hline Pau Brasil & Caesalpinea echinata \\
\hline Pitanga & Eugenia uniflora \\
\hline Tapiá & Alchornia triplinervia \\
\hline Tarumã & Vitex megapotamica \\
\hline Uva do Japão & Houvenia dulcis \\
\hline Pinheiro brasileiro & Araucária angustifólia \\
\hline Erva Mate & Illex paraguariensis \\
\hline Angico & Parapiptadenia rígida \\
\hline Cedro & Cedrela fissillis \\
\hline Canela Pinha & Ocothea sp. \\
\hline Grevilhe & Grevillea robusta \\
\hline Ariticum & Anona cagans \\
\hline Louro & Cordia trichotoma \\
\hline
\end{tabular}

Os animais encontrados fazem parte da fauna neotropical introduzidos ao horto que vive m em regime "semicativeiro", protegidos por uma cerca a mesma que percorre todo o perímetro do Parque. Estes precisam se adaptar as novas condições, de alimentação, pois recebem alimentação fornecida três vezes por semana, defesa contra predadores.

São encontradas diversas populações de animais que se interagem com a flora, principalmente insetos, répteis e mamíferos tais como (tabela no 02).

Tabela no 02: animais encontrados no horto.

\begin{tabular}{|l|l|}
\hline \multicolumn{1}{|c|}{ NOME POPULAR } & \multicolumn{1}{c|}{ NOME CIENTÍFICO } \\
\hline Capivara & Hidrochuerus hidrochaeris \\
\hline Cateto & Tayassu tajacu \\
\hline Cutia & Cutia nipalensis \\
\hline Gambá & Didelphus sp \\
\hline Graxaim & Cerdycyon thous \\
\hline Libélula & Ordem - Odonata \\
\hline Borboleta & Ordem - Lepidóptera \\
\hline Formiga & Ordem - Hemynoptera \\
\hline Vespa & Ordem - Hemynoptera \\
\hline
\end{tabular}


da Alta Paulista

\begin{tabular}{|l|l|}
\hline Abelha & Apis $s p$ \\
\hline Lagarto & Teiús $s p$ \\
\hline Morcego & Myotis nigricans \\
\hline Quati & Nasua nasua \\
\hline Ratão-do-banhado & Myocastor coypus \\
\hline Jaboti & Gopheurs sp \\
\hline Tatu peba & Euphractus sexcinctus \\
\hline Veado catingueiro & Mazama gouazoubira \\
\hline
\end{tabular}

Os estudos fitossociológicos, e ecológicos revelaram:

1) A canafístula (Pelthophorum dubium) como espécie que possui a maior densidade, número de indivíduos, dominância e diâmetro;

2) As maiores alturas foram encontradas em exemplares de eucalipto (Eucalipto $s p$ ), seguidas pelas espécies como loro, cedro, uva-do-japão.

3) Espécies diferentes de vegetais, tais como: Canafístula, aroeira -periquita, ipêamarelo, louro, pinheiro -brasileiro, ingá, pitanga, dividem o mesmo espaço em determinado local e em outro predomi na uma única espécie, tal qual: tapiá ou canelapinha.

4) Conceitos de comunidade ecológica já que o parque exibe várias associações entre grupos vegetais e animais tais como: mutualismo (quati (Nasua nasua) e capivara (Hidrchoerus hydrchoerus), abelhas ( $A$ pis $\mathrm{sp}$ ) e flor de maracujá (Passiflora $s p$ ), canafístua (Pelthphorum dubium) e orquídeas (Oncidium sp)). (Louro (Cor dia Trichotoma) e bromélia (Tillandsia sp)); competição (canafístua (Pelthophorum dubium) e tapiá (Alchornea tripinervia)), parasitismo (cereja (Eugenia involucrata) e erva de passarinho (Psittacanthus sp);

5) O conceito de ecologia comportamental observados principalmente no forrageamento, corte cuidado com a cria, defesa e comunicação, apresentado pelas espécies de mamíferos que constituem o parque, sendo estas capivaras (Hydrocherus hydrocherus), catetos (Tayassu tajacu) e quati (Nasua nasua); (6) A avifauna, é pouco diversificada, não residente (portanto transitória), em função da diversidade de ocupação de nichos já habitados por predadores não consegui formar ninhos, pois os mesmos são atacados pelo quati.

7) O solo apresenta uma gradação de situação (solo latossolo roxo, solo turfoso e áreas aterradas), pois parte da área que forma o horto florestal do parque foi aterrado e 
parte é formada por solo turfo. Tendo como predominância latossolo roxo eutrofico (Ir), é um solo não hidromórfico.

A partir do estudo da fitossociologia do Parque foi possível identificar sete regiões de distribuição da vegetação, foram estas:

1) O Portão de entrada, onde se encontram diversas espécies de plantas, principalmente frutíferas como: pitanga, araçá, goiaba, uva-do-japão, amora e cereja, com presença de alguns arbustos, suas características são apresentadas pelo espaço que existe entre uma árvore e outra, o chão é bem batido, representando que o local é constantemente utilizado. Os animais buscam este local logo após a alimentação com finalidade de descansar e para realizar o grumin.

2) uma região alagada, a Sanga Panambi, com área de 0,10 ha, um dos fornecedores de água para os lagos municipais, poupados com a finalidade de suprimento das necessidades da fauna existente, não há peixes, pois, a mesma possui grande quantidade de matéria orgânica e grande teor ácido. Observações mais detalhadas mostraram que uma porção da sanga apresenta uma maior viscosidade, deixando a mesma mais densa.

O solo a sua margem é turfoso e ácido, sendo preenchido de pteridófitas, única planta que consegue se desenvolver num solo com estas características, pois não há vestígios de desenvolvimento de outras plantas, que são inibidas no solo. Os animais que vivem nesta vegetação são os de pequeno porte, como tatu, jabuti, libélulas que passam a fase de acasalamento e reprodução e, ratão-do-banhado, que faz suas tocas a margem da sanga.

3) logo após encontra-se uma região intermediaria, marcada pela diminuição de pteridófitas que agora estão em menor quantidade e que dividem espaço com gramíneas, arbustos e árvores de médio porte, que ficam uma distância significante.

O solo apresenta uma coloração roxa, sinais de melhores condições menores acidez e melhor ao nível de nutrientes. À frente, localiza-se uma diversidade de Myrtaceae bem desenvolvidas, mas com características totalmente diferentes do normal, seu caule curto e ramificado tem densa copa, se assemelham com plantas de mangue, is to devido a abundante quantidade de água existente abaixo da planta.

4) Extrato superior, árvores de médio à grande porte, tais como: tapiá, tipuana, cedro, erva-mate, com diâmetros superiores a $50 \mathrm{~cm}$ e alturas que variam de 4 a 12 metros, é observado competição entre as plantas por luz, uma vez que algumas apresentam caules longos, e folhas apenas nas copas e de maior tamanho, isto para absorverem maior luminosidade para seus processos metabólicos. Inúmeras plantinhas são vistas ao redor de suas plantas mãe, sinal de uma florada de sucesso e boa germinação, mas 
estas passaram por diversas etapas nas quais apenas as melhores conseguiram se desenvolver, sendo que de 500 apenas 1 chegara ao tamanho adulto. Neste local é observado o ataque das capivaras sobre o caule de algumas plantas para demarcar seu território.

5) Após este local se observa uma região com maiores inclinações de solo. Aqui são observadas dezenas de tocas de tatu e as marcas de um dos drenos, mostradas pela diferença de altura, plantas de grande porte. Povoado por borboletas, que ficam pousadas sobre o caule, usando a técnica de mimetismo. Outro animal já observado no local é aranha do buraco, aracnídeo que faz seu ninho com pedaços de folhas, e pequenos galhinhos do tamanho de $5-7 \mathrm{~cm}$, que ficam ligados por teias até o ninho, onde se encontra o animal escondido, quando a presa toca na armadilha ela rapidamente desenvolve ataque em direção da presa.

6) Região que conserva características das plantas nativas, naturais da região, domínio de arbusto, gramínea e plantas trepadeiras, de difícil acesso, habitadas por populações de insetos e pequenos animais, privilegiados pela disponibilidade luminosa, recebe todo o sol da manhã e um terço da tarde. Ao anoitecer recebe a visita de morcegos que buscam abrigo nas árvores que ficam mais ao centro.

7) Região aberta, sem a presença de árvores, local de encontro de todos os animais, que vem se alimentar. Alimento este fornecido pela prefeitura que traz dos supermercados frutas e legumes, três vezes por semana, ponto procurado por estudantes que querem desenvolver estudos sobre comportamento.

\subsection{Criação de um modelo educativo para fins didáticos para o Parque}

O Parque Ecológico favorece a produção de um modelo pedagógico constituído de duas partes vistas como linhas de ação:

(A) Formação e interpretação ambiental a partir dos conceitos ecológicos construídos a partir das observacões feitas na trilha do Parque:

Esta linha de ação envolve a promoção de cursos vinculados a visitas guiadas e estudo de campo, com a participação de professores (as) e alunos (as) do nível fundamental, médio ou superior. Foram identificados os seguintes itens possíveis de serem utilizados na área de ensino de ecologia e educação ambiental:

1. Os conceitos de fatores ecológicos extraídos da ecologia fisiológica ligada aos constituintes edáficos, já que o parque apresenta uma gradação de situação de solo (solo 
latossolo roxo, solo turfoso e área aterradas) é uma diversidade de adaptações de vegetais e suas variações.

2. Os conceitos de ecologia de população, sobretudo no que tange a flora, em que grupos de diferentes espécies de vegetais, dividem o mesmo espaço em determinados locais, tais como; canafístula (Pelthophorum dubium), aroeira periquita (Chinus terenbentifolius), ipê amarelo (Tabebuia crisotricha), louro (Cordia trichotoma), pinheiro brasileiro (Araucária angustifólia), ingá (Inga sessiles), pitanga (Eugenia uniflora), tápia (Alchornea triplinervia). E, em outros locais, predomina uma única espécie, tal qual: tápia (Alchornea triplinervia) ou canela pinha (Ocothonea sp).

3. Os conceitos de comunidade ecológica, já que o parque exibe várias associações entre grupos de vegetais e animais tais como: mutualismo [quati (Nasua nasua) e capivaras (Hydrochoerus hydrochoerus), abelha (Apis sp) e flor de maracujá (Passiflora $s p$ ), canafístula (Pelthophorum dubium) e orquídeas (Onadium sp), louro (Cordia trichotoma) e bromélias (Tillandsia sp), competição [cafítula (Pelthophorum dubuim) e tápia (Alchornea triplinervia)],parasitismo [cereja (Eugenia involucrata) e erva de passarinho (Psittacanthus sp)], predação [quati (Nasua nasua) e tartaruga (Chrysemys sp) e pomba (Columbi sp)].

4. Os conceitos de ecologia comportamental observados principalmente na organização social, forrageamento, corte, cuidado com a cria, defesa e comunicação, apresentado pelas espécies de mamíferos que constituem o parque. Sendo estas: capivaras (Hydrochoerus hydrochoerus), catetos (Tayassuldae sp ), quati (Nasua nasua), Graxaim (Cerdycyon thous), Cutia (Cutia nipalensis), Ratão-do-banhado (Myocastor coypus), Tatu peba (Euphractus sexcinctus) e Veado catingueiro (Mazama goazoubira)

5. Foi possível observar o comportamento de bandos de quatis (Nasua nasua). Estes animais apresentaram comportamento altamente ativo, encontrando-se grupos de até 53 animais realizando numerosas atividades, sendo estas: busca por alimento (forrageamento); defesa de território; cuidados com a prole; reprodução; côrte; "grooming"; mudança de ninhos; seleção de árvores; distribuição espacial dos ninhos; sinais de alerta e migração dentro e fora do espaço do parque.

6. Quanto às capivaras, foi identificado sua preferência alimentar na vegetação do parque. Assim foram: o jacarandá (Jacaranda sp.), ipê amarelo (Tabebuia chrysotricha), o ipê roxo (Tabebuia avellanedae), o fedegoso (Cassia sp.), a canafístula (Peltophorum dubium), tipuana (Tipuana tipu), abacateiro (Persea americana), leucena (leucaena leococephala), guabiroba-do-mato (Campomanesia xanthocarpa), pitangueira (Eugenia uniflora), araçazeiro-do-campo (Psidium catteyanum), uva-japonesa (Ligustrum japonicum), pessegueiro (Prunus persica) e o tarumã (Vitex montevidensis). Estes roedores alimentavam-se, especialmente, das plântulas, da casca e dos frutos das plantas citadas 
acima e também das folhas secas de todas as espécies vegetais encontradas no Horto, exceto eucalipto (Eucalyptus sp.) e erva-mate (Ilex paraguariensis).

7. Durante as observações constatou-se uma profunda interação social do tipo "grooming" entre os quatis e as capivaras. Os padrões motores exibidos pelos quatis e envolviam as capivaras, foram os que o quati se deslocava intencionalmente em direção a uma capivara imóvel dentro do grupo e ao tocá-la a capivara expunha o dorso, o flanco e em seguida o ventre enquanto o quati continuava o seu "grooming" por 10 a 20 minutos. Em seguida o quati abandonava a capivara que continuava na posição de descanso.

(B) Desenvolvimento de materiais pedagógicos produzidos a partir dos conceitos ecológicos construídos nestas observacões.

Os materiais desenvolvidos foram: jogo de trilha, quebra-cabeça, dominó e jogo-davelha. Além de materiais artísticos como teatro de máscaras e pinturas. As ações citadas visaram articular e integrar os segmentos internos e externos à UC como: professores (as), estudantes, pesquisadores (as), técnicos (as), população do entorno, entre outros atores sociais, na perspectiva de contribuir para a construção e ampliação de sua consciência, visando à participação de cidadãos e cidadãs na defesa do meio ambiente e na melhoria da qualidade de vida.

\section{CONCLUSÃo}

O Parque Ecológico Diva Paim Barth pode ser considerado uma área adequada para ser utilizada como um laboratório natural fornecedor de modelos ecológicos e de educação ambiental possíveis de serem explorados por professores e alunos e partindo de características regionais, aumentando o conhecimento sobre a flora e fauna e a consciência sobre as questões ambientais e o espírito de cidadão.

\section{REFERÊNCIAS BIBLIOGRÁFICAS}

CALLAI, Helena C. O meio ambiente no ensino fundamental. Espaço da Escola, ljuí, v. 4, n. 27, p.31- 42, 1998.

COLOGNESE, A. L. Desempenho da Irrigação de um Sistema Pivô Central, Sob Condições de Plantio Direto, no Município de Palotina - Pr. Cascavel, Paraná, 1999. Dissertação de Mestrado.

COLOGNESE, A. L; NASCIMENTO JÚNIOR, A. F.; LUNKES, J. E.; TEIXEIRA, V. L.; GOELZER, L. P. Cartoon ecológico como subsídio ao ensino de ecologia e educação ambiental para alunos do ensino fundamental e médio. In: I Seminário Internacional de 
Educação, 2001, Cianorte-PR.

ELLMBERG, H.; MULLER-DOMBOIS, D. A key to raunkiaer plant life forms with revised subdivisions. Ber. Geobot. Inst. ETH, stiffing Ruble, Zurich. 37: 21-55, 1965/66.

KLEIN, J.; KESTRING, D.; QUEIROZ, A.; NASCIMENTO JÚNIOR, A. F.; A utilização de animais em miniatura como forma de ensino de ciências. In: $26^{\circ}$ Congresso de Zoológicos do Brasil e $2^{\circ}$ Encontro de Zôos do Mercosul 2002, Porto Alegre-RS.

MILANO, M. S. Curso sobre Manejo de Áreas Naturais Protegidas. Curitiba, Universidade Livre do Meio Ambiente. 1993, p: 1-62. (apostila).

PORTO, M. de F. M. M. Educação Ambiental: conceitos básicos e instrumentos de ação. Manual de saneamento e proteção ambiental para os municípios. Belo Horizonte: Fundação Estadual do Meio Ambiente, DESA/ UFMG, 1996.

SANTIAGO, S. H. M.; SAITO, Carlos. Educação ambiental e cidadania: o lixo como eixo condutor de uma leitura integrada da realidade social. Revista do Centro De Educação. Santa Maria, v. 20, n. 2, p. 64- 82, 1995.

SILVA, C. E. F. Legislação Conservacionista e sua Correlação com o Planejamento para Unidades de Conservação da Natureza. Secretaria do Meio Ambiente. Instituto Florestal, SP, 1993.

VASCONCELLO, J. Trilhas interpretativas como instrumento de educação. In: Curso de atividades Ecológicas II - Trilhas Interpretativas. UNILIVRE, Curitiba, PR, p 1-20. 1997. 